Original Research Paper

\title{
Realizing the Impact of Cognitive Dissonance in Predicting Consumer Behaviour
}

\author{
Akhilesh Chandra Pandey and Mohit Jamwal \\ HNB Garhwal University, Srinagar Garhwal, Uttarakhand, India
}

\author{
Article history \\ Received: 10-03-2015 \\ Revised: 11-05-2015 \\ Accepted: 05-06-2015 \\ Corresponding Author: \\ Mohit Jamwal \\ HNB Garhwal University, \\ Srinagar Garhwal, Uttarakhand, \\ India \\ Email: mohit.jamwal88@rediffmail.com
}

\begin{abstract}
Consumer psychology has always been the centre of concern for the marketers from the old time and understanding the underlying aspects leads to effective decision making. The present study elicits the concept of post purchase cognitive dissonance in the consumers and embraces its implications in studying the consumer behaviour. A survey was conducted and well framed questionnaire was constructed covering various dimensions of variables studied. Some of the underlying dimensions of cognitive dissonance have been rigorously discussed and statistically tested in this study. Specifically, the impact of product involvement, time taken to make a purchase decision and level of information search on the cognitive dissonance have been analysed that provides really significant benefits to the marketers.
\end{abstract}

Keywords: Cognitive Dissonance, Consumer Psychology, Post Purchase Dissonance

\section{Introduction}

Understanding Consumer Behaviour is a significant approach in every marketing strategy of a firm and therefore, a comprehensive examination of the various dimensions and aspects has to be done for the organisation's success. Although, enough care has to be taken in strategy implementation at each step, various marketers are even more worried about the post consumption phase of the product or service. This is the time when the consumers' show their like/dislike for the product and lead to patronage towards the product and the company. One such dimension which impacts the patronage or repurchase is the level of consonance or dissonance developed towards the purchase.

The dissonance may be developed in pre-decisional phase in the consumer's decision making process due to the various forgone competitor's product features against in the purchased ones (Koller and Salzberger, 2007) or in the post purchase phase due to the disconfirmation of initial expectations about the product. This leads to stage of cognitive dissonance which comes in existence when a consumer become confused on the two beliefs held by him that cannot exist together and creates a psychological discomfort for him. The resulting discomfort motivates the individual to reduce the tension already developed by some means. This refers to the one of the social psychology's greatest theories known as the Theory of Cognitive dissonance (Festinger, 1957). Dissonance is mainly experienced by three main means:
Firstly if there is any logical inconsistency exists in the consumer's mind. Secondly, if there is disagreement between two different attitudes or behaviours. Thirdly, dissonance may also occur after disconfirmation of a strongly held belief (Loudon, 1993). Now if dissonance arises, a person feels uncomfortable and finds ways to reduce this psychological discomfort. There are several ways in which the consumer strives to reduce dissonance. First, he may change his evaluation of alternative. Second, he may seek new information to support his choice and thirdly, he may change his attitudes. Therefore, the personal characteristics of the customer may have a significant impact on the postpurchase behaviour due to the dynamic psychological changes incur in their minds (evaluation of products).

\section{Literature Review}

Human mind always have a curiosity to assess the value generated after the consumption of a product or a service. Senses of contradicting thoughts are generated in consumer's mind that evaluates the features of product purchased and the foregone competitor's offering benefits. These persuasions keep on striking in the consumer's mind, make him unwell and rethink about the purchase whether it was a wise or poor decision (Kassarjian and Cohen, 1965).

Consumer decision making process involves various steps and depending upon the involvement of the product, a customer performs activities at all the steps or 
may omit certain steps. The more the expectations before the purchase, the more will be the favourable evaluation in products which involve high consumer involvement (Korgaonkar and Moschis, 1982). A customer after purchasing a certain product may feel that buying competitors' product could have been a smart choice. This belief also gets strengthened after the expectations of the customer get disconfirmed. In such a situation, the patronage towards the product or the company could be under scanner and the person may find the positive features of the purchased product as superfluous. When the inconsistencies are experienced by buyers, they feel discontented and make change to reduce the dissonance and achieve harmony. Arronson (1997) propounded it as negative driver condition.

Although the concept of cognitive dissonance has often been used to discuss post-purchase phenomena, the empirical study conducted by Koller and Salzberger (2007) suggested that cognitive dissonance is also applicable to the pre-purchase stage of consumer behaviour. They investigated the variance of dissonance in all stages of consumer decision making by doing research on tourists visiting hotels. Consumers always take into consideration the previous experience with the product before purchasing a new product. The gap between expectations from purchase and prior experience increases with time and this led to perceptions of the earlier experience to decline and hence causes cognitive dissonance (O'Neill and Palmer, 2004).

Studies have found that the buyers who switch brands frequently repent more than the others who don't (Keaveney et al., 2007). Recent researches also showed that the customers buying household appliances feels post purchase dissonance because of the large amount of time been spend to search the information about them and then finally coming to a decision (Westbrook and Newman, 1978). Therefore, it cannot be said that the highly informed customers cannot experience post purchase dissonance.

\section{The Proposed Hypothesis}

\section{Product Involvement}

The present view of involvement applies to be an inciting variable that can shape a consumer's purchases and ultimately their behavior. Product involvement simply refers to the perceived personal relevance of a product to an individual, based on inherent needs, values and interests (Antil, 1984; Zaichkowsky, 1985). It can simply be defined as the general concern for the product or the position of the product in the person's ego structure (Day, 1970). Moreover, the level of involvement finds out the broadness and complexity of consumer's purchase decision making process (Kapferer and Laurent, 1985).
Previous research reveals that dissonance is a kind of cognitive tension state that arises whenever the expected performance is not delivered by the product (Festinger, 1957). The low involvement products have been found to induce strong post purchase dissonance than high involvement products (Gbadamosi, 2009):

$\mathrm{H}_{0} 1$ : More the involvement of the product, more the dissonance will be experienced.

\section{Time Taken in Purchase}

Cognitive dissonance is a situation that prevails when there are two or more conflicting thoughts at the same time. It is seen that dissonance is associated with time while a decision is made. The time variable makes the customers to opt for very unintentional decisions that are not supposed to be made (Rook and Fisher, 1995). This may result in some impulsive buying tendencies by the customers. Often, it is expected that a well-planned decision making process will lead to less dissonance in the long run:

$\mathrm{H}_{0}$ 2: There is a significant difference between the time taken to make a purchase decision and dissonance experienced by a consumer. Specifically, more the time taken in making a decision, more the dissonance felt.

\section{Level of Information Search}

Customers goes for high level of information search whenever they indulge themselves in a rigorous extensive decision making process. High information search involves both internal and external search. Internal search finds the past experiences with the purchase/product while the external search is the process of seeking information from the outside environment. Therefore, the high information search would mostly lead to lesser post purchase cognitive dissonance due to better decision making. The null hypothesis can be posted as:

$\mathrm{H}_{0}$ 3: There is a significant difference in cognitive dissonance associated with a higher information search than with a low level of information search effort carried out by the consumer on purchase of durables. Higher the information search, higher the dissonance and vice versa.

The research hypotheses have been incorporated into conceptual framework of the study as shown in Fig.1.

\section{Research Methodology}

The study investigated the different characteristics of consumer behaviour in purchase of durables. The primary data was collected through a survey done in Delhi-NCR 
region comprising of 220 respondents. The research instrument used is questionnaire that is constructed based on the previous work done on similar studies. The dimension of cognitive dissonance was measured on a 7 point semantic differential scale propounded by Sweeney et al. (2000). A total of 220 questionnaires were distributed to respondents on purchase of durables. Out of 220 , four were not able to trace while ten were found redundant due to non-response and missing fields. Therefore, 14 questionnaires were discarded in the study. The analysis of data was done to accept or reject the hypotheses through SPSS 17.0.

\section{Data Analysis and Discussion}

\section{Sample Characteristics}

Out of the total sample of 220 respondents, 14 were discarded due to non-response errors and missing fields. A total of $131(63.6 \%)$ respondents were males while 75 (36.4\%) were females. Most $(49.5 \%)$ of the respondents were graduates, $32.0 \%$ were post graduates and $18.4 \%$ were undergraduates. The age distribution of respondents was evenly poised with mean 2.0728 while majority $(43.2 \%)$ of the respondents were included in the income group of 3-6 lakh as depicted in the Table 1 shown below.

\section{Reliability of Scale}

Self-administered questionnaire was used in the study various constructs used to measure the variables under study were taken from the researches done in the past.
Cognitive dissonance was measured using the measurement scale given by Sweeney et al. (2000). Three underlying constructs of dissonance were measured-Emotional dissonance, wisdom of purchase and Concern over the deal. The overall reliability of the questionnaire was measure by Cronbach's alpha, which is a measure of internal consistency, that is, how closely related a set of items are as a group. A "high" value of alpha is often used (along with substantive arguments and possibly other statistical measures) as evidence that the items measure an underlying (or latent) construct. Happily, the overall value of Cronbach's alpha was found out to be 0.848 as shown in the Table 2 .

The three formally framed hypotheses were statistically tested by using a well-structured questionnaire and thereafter, results were subjected to analysis and interpretations.

The first hypothesis predicts the relationship between the cognitive dissonance experienced by the consumer and the involvement of the product. Kruskal Wallis test was implied and the results were found to be significant ( $p$ value $=0.000)$. Product involvement was taken as grouping variable and various statements exhibiting dissonance felt were tested against it as shown in the Table 3 . The study showed that the product involvement inversely relates to the level of dissonance felt by a consumer. It signifies that the more a customer engages himself in the purchase of product, the better he attaches with the product. This serves as an emotional and cognitive bonding of the consumer with the product as a result will less gets dissonant compared to low involvement with the product.

Table 1. Demographic characteristics of sample

\begin{tabular}{llccc}
\hline Sample variables & Items & Frequency & Percentage & Mean \\
\hline Gender & Male & 131 & 63.6 & 1.3641 \\
Education & Female & 75 & 36.4 & 2.1359 \\
& Undergraduate & 38 & 18.4 & 49.5 \\
Age & Graduate & 102 & 32.0 & 2.0728 \\
& Post Graduate & 66 & 31.6 & 37.9 \\
Income & 20-35 years & 65 & 22.3 & \\
& 36-50 years & 78 & 8.3 & 2.3544 \\
& 51-65 years & 46 & 17.5 & \\
& More than 65 years & 17 & 43.2 & \\
& Less than 3 lakh & 36 & 25.7 & 13.6 \\
\hline
\end{tabular}

Table 2. Reliability of a scale

\begin{tabular}{lll}
\hline Variable/scale & Dimension & Cronbach's alpha \\
\hline Cognitive dissonance & Emotional dissonance & 0.734 \\
& Wisdom of purchase & 0.729 \\
& Concern over the deal & 0.784 \\
Product involvement & - & 0.836 \\
Time period after purchase & - & 0.674 \\
Level of information search & - & 0.719 \\
& Overall cronbach's alpha: & 0.848 \\
\hline
\end{tabular}


Table 3. Kruskal Wallis analysis

\begin{tabular}{lcc}
\hline & Test statistics & \\
& I never think over my purchase decision & I wonder if I have made the right choice \\
\hline Chi-square & 26.766 & 25.262 \\
df & 4.000 & 4.000 \\
Asymp. Sig. & 0.000 & 0.000 \\
\hline
\end{tabular}

${ }^{\mathrm{a}}$ Kruskal Wallis test

${ }^{\mathrm{b}}$ Grouping variable: Product involvement

Table 4. Kruskal Wallis analysis

\begin{tabular}{lc}
\hline & Test statistics ${ }^{\mathrm{a}, \mathrm{b}}$ \\
\hline Chi-square & I think I have made the right choice in purchasing the product \\
df & 15.366 \\
Asymp. Sig. & 2.000 \\
\hline
\end{tabular}

${ }^{\mathrm{a} K r u s k a l ~ W a l l i s ~ t e s t ~}$

${ }^{\mathrm{b}}$ Grouping variable: Time period

Table 5. Kruskal Wallis analysis

\begin{tabular}{lll}
\multicolumn{3}{l}{ Table 5. Kruskal Wallis analysis } \\
& Test statistics & \\
& I never think over my purchase decision & I think I have made the right choice in purchasing the product \\
\hline Chi-square & 27.601 & 21.625 \\
df & 4.000 & 4.000 \\
Asymp. Sig. & 0.000 & 0.000 \\
\hline
\end{tabular}

${ }^{\mathrm{a}}$ Kruskal Wallis test

${ }^{\mathrm{b}}$ Grouping variable: Level of information search before purchasing a product

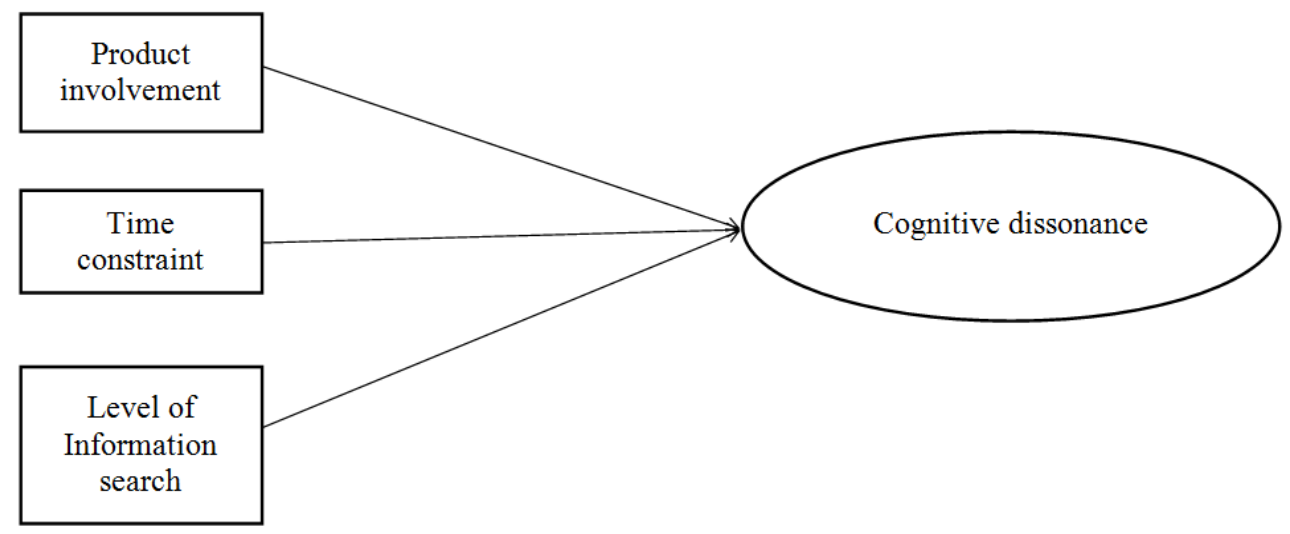

Fig. 1. Conceptual framework

The dissonance was tested against the amount of time taken by a consumer in making a purchase decision and the results showed that a significant $p$ value $(0.000<0.05)$ leading to rejection of null hypothesis as shown in the Table 4 . The grouping variable was 'time period in making a purchase decision' and was measured as high, moderate and Low.

The study revealed that the dissonance decreases as the customer takes more time in making a purchase decision and vice versa. Considering more time, a customer can evaluate more offerings from different competitors and based on this, can judge a wise purchase decision that would lesser dissonance after post-purchase.

The third hypothesis examined the relationship between the dissonance and level of information search done in purchasing a product. The study brings out that more a person indulges himself in rigorous information search before a purchase, the more he become aware of the pros and cons of different competitor's product and therefore, the post purchase dissonance decreases and vice versa.

Table 5 shows the kruskal Wallis test depicting relationship between the level of information search as 
grouping variable and cognitive dissonance. The p-value obtained is 0.000 that is significant leading to rejection of null hypothesis.

\section{Conclusions and Recommendations}

The present study elicits the concept of post purchase cognitive dissonance in the consumers and embraces its implications in studying the consumer behaviour. Consumer psychology has always been the centre of concern for the marketers from the old time and understanding the underlying aspects leads to effective decision making. Therefore, this study also tries to enhance the knowledge of various aspects of post purchase dissonance in relation to information search, time taken in making a purchase decision and product involvement. The study concluded that dissonance decreases as the time taken to make a purchase decision increases. Marketers should engage the customers with more information in their offerings that could lead to a delay in the final purchase by the customers. The more time a seller engages to a customer, the more information a seller will carry on to the buyer, which, finally lead to the contentment to the customer.

The product involvement had found to very significant impact on the dissonance. More the involvement of the product, the dissonance felt would be lesser and vice versa. Therefore, firms should try to position their product as they become not only cognitively but also emotionally bondable to the customers. Moreover, the level of dissonance is different from person to person due to the different threshold levels of experiencing the post-purchase dissatisfaction. In such a case, it becomes very imperative for the company to help the customers diluting their dissonance levels by communicating such details that helps them in building confidence about the product purchase. Hence, the marketers should enlighten the customers by initiating programmes that could satiate the customers.

Because post purchase dissonance is a negative feeling, most customers take measures during the purchase process to minimise it. In fact rather than taking the decision straight way, some customers postpone the decision to an uncertain time. Therefore, the marketers must implement strategies that help in battling these uncomfortable feelings and assure them that they had made the right choice in their purchase. More specifically the marketers should attach emotional content with the brands (Jamwal and Soodan, 2014). The more, positive experiences and moments a marketer shares with the brand, the more likely the customers are likely to become loyal towards a brand.

When attitudes are consistent with purchase behaviour, they are likely to change. Marketers may attempt to induce certain behavioural changes in customers through various promotional tools including free samples and coupons that would assist in ending the buying process on a happy note. Post-purchase information seeking behaviour of customers is usually the result of cognitive dissonance. It would be wise to design the ads that will reinforce the buyers. This method is specifically helpful in targeting new customers and that the company is marketing an innovative product. Also, the most significant is that the product should meet the expectations of the customers. Marketers should not develop expectations unrealistically. In today's world, the advertisements may look like a benignant magnification but it can create an impractical expectations in the customer's mind due to which negative word of mouth can be spread about the product. Therefore, the marketers should be very careful in what they are communicating with the customers.

\section{Scope of Further Research}

The dimensions of cognitive dissonance have huge implications and scope for marketing firms. Although, various causes of cognitive dissonance has been tried to cover but still other variables like customer engagement and after sales services can be find out. Moreover, the relationship of cognitive dissonance with other dimensions of post purchase (viz. satisfaction, complaint behaviour etc.), can be studied. Modern era is an age of online purchase. Therefore, this study also offers novelty to the insights for further research in the online purchasing. It can be examined whether in online purchase, the duration of time and product involvement has an impact on the cognitive dissonance as well. Also, it can be checked that the online purchasing can also have different layers of dissonant customers just like purchasing through a physical store.

\section{Acknowledgment}

The researchers are thankful to the respondents who participated in the survey and cordially cooperated in furnishing the information.

\section{Author's Contributions}

Mohit Jawmal: Conceptual framework, questionnaire preparation and data collection, data analysis, tables preparations maintaining correspondence with editor.

Akhilesh Vhandra Pandey: Final manuscript preparation, Supervise questionnaire preparation and data collection and editing the manuscript.

\section{Ethics}

This article is original and contains unpublished material. The corresponding author confirms that both 
the authors have read and approved the manuscript and no ethical issues involved.

\section{References}

Antil, J.H., 1984. Conceptualization and operationalization of involvement. Adv. Consumer Res., 11: 203-209.

Arronson, E., 1997. Back to the future: Retrospective review of leon festinger's "a theory of cognitive dissonance”. Am. J. Psychol., 110: 127-137. DOI: $10.2307 / 1423706$

Day, G.S., 1970. Buyer Attitudes and Brand Choice Behavior. 1st Edn., Free Press, New York, ISBN-10: 0029072107, pp: 219.

Festinger, L., 1957. A Theory of Cognitive Dissonance. 1st Edn., Stanford University Press, California.

Gbadamosi, A., 2009. Cognitive dissonance: The implicit explication in low-income consumers' shopping behaviour for "low-involvement" grocery products. Int. J. Retail Distribut. Manage., 37: 1077-1095. DOI: $10.1108 / 09590550911005038$

Jamwal, M. and V. Soodan, 2014. Emotional branding as tool for dissonance reduction: A strategy for competitive advantage. Abhinav-Int. Monthly Refereed J. Res. Manage. Technol., 3: 25-32.

Kapferer, J.N. and G. Laurent, 1985. Consumers' involvement profile: New empirical results. Adv. Consumer Res., 12: 290-295.

Kassarjian, H.H. and J.B. Cohen, 1965. Cognitive dissonance and consumer behavior. California Manage. Rev., 8: 55-64. DOI: 10.2307/41165660

Keaveney, S.M., F. Huber and A. Herrmann, 2007. A model of buyer regret: Selected prepurchase and postpurchase antecedents with consequences for the brand and the channel. J. Bus. Res., 60: 1207-1215. DOI: 10.1016/j.jbusres.2006.07.005
Koller, M. and T. Salzberger, 2007. Cognitive dissonance as a relevant construct throughout the decision-making and consumption process-an empirical investigation related to a package tour. J. Customer Behav., 6: 217-227. DOI: $10.1362 / 147539207 X 251022$

Korgaonkar, K.P. and G.P. Moschis, 1982. An experimental study of cognitive dissonance, product involvement, expectations, performance and consumer judgement of product performance. J. Advertis., 11: 32-44. DOI: $10.1080 / 00913367.1982 .10672810$

Loudon, D.L., 1993. Consumer Behavior: Concepts and Applications. 4th Edn., McGraw-Hill, New York, ISBN-10: 0070387672, pp: 788.

O'Neill, M. and A. Palmer, 2004. Cognitive dissonance and the stability of service quality perceptions. J. Services Market., 18: 433-449. DOI: $10.1108 / 08876040410557221$

Rook, D.W. and R.J. Fisher, 1995. Normative influences on impulsive buying behavior. J. Consumer Res., 22: 305-313. DOI: 10.1086/209452

Sweeney, J.C., D. Hausknecht and G.N. Soutar, 2000. Cognitive dissonance after purchase: A multidimensional scale. Psychol. Market., 17: 369-385. DOI: $10.1002 /($ SICI) $1520-$ 6793(200005)17:5<369::AID-MAR1>3.0.CO;2-G

Westbrook, R.A. and J.W. Newman, 1978. An analysis of shopper dissatisfaction for major household appliances. J. Market. Res., 15: 456-466. DOI: $10.2307 / 3150594$

Zaichkowsky, J.L., 1985. Measuring the involvement construct. J. Consumer Res., 12: 341-52. DOI: $10.1086 / 208520$ 